In the line of working aluminium, the Heraeus process of welding aluminium deserves to be highly spokeh of. It is the invention of W. C. Heraeus, of Hanau, Germany, and was represented in the German section by a collection of wires, rods, sheet vessels and urns, with perfectly welded seams. The process is operated without solder or flux of any kind, and consists, according to the inventor, in merely cleaning the surfaces to be joined, laying together, heating carefully to the temperature at which the metal commences to soften, keeping at that temperature and meanwhile hammering together to a perfect weld. The process is thus seen to be that of autogeneous soldering. The inventor lays stress on the fact that the temperature must be kept constant; that if it rises too high the metal becomes short or granular, and also commences to oxidize, which conditions defeat the welding. It is merely a question of maintaining the joint by a blowpipe at the proper temperature of incipient softening and hammering together to a weld.

The samples shown were certainly very well done, and the process opens up a new era in the methods of working aluminium.

\title{
ON THE CLASSIFICATION OF CRUDE PETROLEUMS.*
}

By S. F. Peckfam.

In the famous report made in 1855 by Prof. Benjamin Silliman, Jr., upon the petroletum of Venango County, $\mathrm{Pa}$, he says, while commenting upon the different boiling points of the different fractions obtained by fractional distillation:

"The uncertainty of the boiling points indicates that the products obtained at the temperatures named above were still mixtures of others, and the question forces itself upon us whether these several oils are to be regarded as educts (i. e., bodies previously existing and simply separated in the

* Read at the Petroleum Congress, held at Paris, France, August 25, I900, and revised for publication in the Journal. 
process of distillation), or whether they are not rather produced by the heat and chemical change in the process of distillation."

Further on in the report, when discussing one of the heroin distillates, he says :

"The paraffine with which this portion of the oil abounds does not exist ready-formed in the original crude product, but it is the result of the high temperature employed in the process of distillation, by which the elements are mostly arranged."

* * * "Associated with paraffine are portions of a very volatile oil, eupione, which boils at a lower temperature, and by its presence renders the boiling point of the mixture difficult to determine."1

Previous to the date of this report the naphtha of Amiano had been examined by De Saussure in $1817,{ }^{2}$ and the maltha of Bechelbronn had been examined by Botussingault in I $837 .^{3}$

Up to the time Professor Silliman made this report, petroleum or rock oil had been regarded as a species by both geologists and chemists. As late as 1859 Dr. J. S. Newbury wrote upon "The Rock Oils of Ohio," and in 1862 Dr. T. Sterry Hunt had written "On the History of Petroleum, or Rock Oil,"s basing his discussion on his experiences in Canada.

Still later, in 1876 , Dr. J. Lawrence Smith concludes that Professor Silliman, in 1855 , was the first person who observed the phenomena attending the destructive distillation of petroleum. ${ }^{6}$

It is now believed that Pelouze and Cahours, in I863, examined Canadian petroleum. ${ }^{7}$ At the same time, and later, Warren alone, and associated with Storer, confirmed the results obtained by the French chemists, and obtained by means of Warren's superior process of condensation a more complete insight into the composition of the hydrocarbons constituting American and Rangoon petroleum. These results, however, were qualitative rather than quantitative, the various substances isolated being practically the same in each of the researches mentioned. 
The conclusion followed naturally that the crude oils varied in character as the proportions of the same materials varied in the different mixtures. The idea that the various substances isolated were products and not educts contributed to this conclusion.

In the memoir written in 1868 by C. M. Warren, and published after his death in 1896, Warren proceeds to criticise the results obtained by Pelouze and Cahours, Ronalds, and others, in comparison with his own, and apparently assumed that the crude material upon which these different parties worked was identical. ${ }^{8}$ If, as has been asserted, Warren worked on petroleum from the vicinity of Titusville, $\mathrm{Pa}$, and the French chemists worked on Canadian petroleum, it is not surprising that the results obtained by the different investigators were unlike.

It was my privilege, during the years from the autumn of 1866 to 1872 , to be on terms of familiar acquaintance with C. M. Warren. A more delightful friend never existed; yet, he was a man who held his opinions with great firmness. He had converted thousands of barrels of petroleum from the wells of Western Pennsylvania into commercial products. He knew that these wells, though drilled many miles apart, furnished oils substantially alike. Moreover, he had made that crucial test, as he supposed; he had destructively distilled menhaden-oil soap, and obtained therefrom petroleum-like compounds. To him petroleum was petroleum, for when I took into his laboratory, in which he and Storer had conducted their now classical researches, the samples of crude petroleum that I had brought from California, he listened with an amused incredulity to my assertions that I had in the cans a new species of petroleum. It was while I was in the midst of my work that he moved his laboratory to his house in Brookline, and I was obliged to finish the work in Providence. I made frequent visits to Brookline to report progress and showed him my results. He said he had examined Professor Silliman's sample of crude California oil and obtained 50 per cent. of light oils. He admitted with reluctance that his sample had been falsified. When I triumphantly assured him that 
by passing gases through Pennsylvania and California petroleums that would deprive them of hydrogen, I could evaporate the first and convert the second into asphaltum, he was still incredulous, and thought my ideas regarding the origin of petroleum expressed in I 868 theoretical, without any substantial basis of fact to rest on. ${ }^{9}$

Although I had no absolute proof thereof, I was firmly convinced in 1868 that the California oils consisted of hydrocarbons containing less hydrogen than was found in those from Pennsylvania. 'It was then impossible for me to obtain a bearing from any of those engaged in investing money in the production of oil in California. The only man who would listen to me was the late Prof. J. D. Whitney, who wanted to send me to Berlin to work the problems up with Hofmann. Professor Whitney had so exasperated the general public on the Pacific Coast by his persistent iteration of the truth regarding petroleum and other interests that they sent him and his geological survey out of the State.

In 1872 Dr. J. S. Newbury published in the American Chemist, II, 427, his "Notes on Ámerican Asphaltum,"10 to which I replied." He spoke of the tar springs of the Southwest as springs of heavy petroleum, while I maintained that maltha, or mineral tar, was not petroleum. Meeting Dr. Newbury, a short time after.I had published my paper, he showed me his large collection of specimens of petroleum from all parts of the world, and challenged me to put my finger on any specimen, from the lightest to the heaviest, that would not mark a purely arbitrary distinction. With Dr. Newbury, petroleum was petroleum, the only difference in specimens being that some were light and some were heavy.

When, in 1880 , I was engaged in collecting the statistics for my report on petroleum to the Tenth Census of the United States, I encountered two significant facts: (I) The investigators of Russian petroleum had discovered that the hydrocarbons that made up the bulk of Russian petroleum were not paraffines with the general formula $\mathrm{C}_{n} \mathrm{H}_{2 \mathrm{n}}+2$, but additive benzoles with the general formula $\mathrm{C}_{n} \mathrm{H}_{2 n}$; (2) 
a correspondent reported that the refiners of California pe. troleum were not making an illuminating oil that could be sold in competition with Eastern oil, but were sending their product to Mexico, where they found a less critical market than in California.

This evidence pointed to sharp distinctions in petroleums from different localities. The wells first struck on Oil Creek and the Alleghany River produced a petroleum easily refined into naphtha, illuminating and lubricating oils; and, while the evolution of the technology of these oils required many years, the movement was along certain well-marked lines, wherein no obstacles were encountered to continued success. The process of cracking, discovered by Joshua Merrill, when working on the distillates from coal, was applied with great success to the Pennsylvania oils, but attempts to apply this method of distillation to the California oils were not found to produce corresponding re. sults, although distillation under pressure did increase the yield of light oils.

Returning to the Pacific Coast in the fall of 1893 , I was soon informed by Dr. Salathe of his discovery of the nitrogenous basic oils in the crude California oils and their distillates. This discovery gave definiteness to facts already known, and led to important results in the technology of those oils. This discovery, too, revived in my own mind convictions formed many years before, that the petroleums of the $\mathrm{Pa}$. cific Coast were specifically different from those of the Mississippi Valley, containing different hydrocarbons, producing different hydrocarbons and requiring different treatment for their successful manipulation. This conviction led to renewed attempts on my part to persuade the owners of large interests in California petroleum to have made a careful and thorough examination of their crude material, with a view to determining the chemical constitution of the oil, the nature and value of its products, and the best methods of securing those products by treatment. These gentlemen still remained unconvinced of the value of such work.

Meantime, the value of a scientific examination of petro. leum was gaining ground in Europe, and exhaustive analyti. 
cal researches were being had upon Russian and other petroleums. The relation and value of these purely scientific researches to technology were gradually recognized and appreciated.

In the United States the production of enormous quantities of Trenton limestone oil, comparatively rich in sulphur, brought to the attention of both chemists and technologists problems that were both new and difficult. These problems led Prof. Charles F. Mabery to take up the investigation of the "Ohio and Canadian Sulphur Petroleums"12 along lines suggested by the researches of Warren, but with superior apparatus, and by methods brought into use by the labors and experience of the thirty years that had intervened between 1865 and 1895 .

The results obtained by Mabery led me, in a memoir published in the Journal of the Franklin Institute for November, I895, to review the generic and specific relations of bitumen. In that paper, that may not be familiar to this audience, I showed that, down to the middle of the present century, the ancient, medieval and modern world had known no generic relation between solid, liquid and gaseous forms of bitumen, but had regarded natural gas, petroleum or rock oil, maltha or mineral tar, and asphaltum, as things by themselves, with neither specific nor generic relations. I then determined that such a classification is purely arbitrary, depending entirely on merely physical accidents, which in no case exhibited either chemical or geological relations. I further urged that the researches of chemists for the then last thirty years had shown that bitumens had generic relations that embraced all forms of bitumen, in the widest sense, and specific relations that embraced all forms of bitumen possessing, within a certain range, the same chemical composition. I then suggested that, while it was possible to regard all forms of bitumen, either gaseous, liquid, semi-solid or solid, as constituting the genus Btumen, it was equally certain that under this genus were to be found several well-defined species that embraced in some instances only the gaseous and liquid forms, like the Pennsylvania and Ohio oils, in other cases all of the 
forms, like the Canadian and California oils, with still others, like grahamite, albertite, gilsonite and Trinidad pitch, that were always solid. I further called attention to the fact that Prof. J. D. Dana had apparently regarded petroleums as rocks rather than species, as he, in his "System of Mineralogy," had inserted Warren's paraffines and isoparaffines as species, while he had also made albertite, grahamite, etc., species. I then showed that there were a number of bituminous minerals that were, strictly speaking, rocks that consisted of loose sand or rock impregnated with bitumen, the bitumen being in some cases a separate species and in other cases referable to a species that usually existed in some of the common forms of bitumen.

I then suggested names for several of these species of bitumen, calling Trinidad pitch parianite, the Pennsylvania paraffine petroleums, warrenite, the Ohio and Canada sulphur petroleums, maberyite, and the California nitrogenous oils, venturaïte.

With this long preamble, largely consisting of personal reminiscence, for which I crave the indulgence of this audience, I would suggest that the mass of materials now at the disposal of the scientific men of all nations should be arranged according to some system that shall be adequate to classify all of the materials now accumulated and sufficiently elastic to receive the acquisitions of the future.

As this subject has occupied my thoughts for many years, I may be pardoned for offering some suggestions. I believe that an adequate system must embrace all forms of bitumen and cannot be confined to petroleums alone. It must begin by creating a sharp distinction between pyrobitumens and their anthracitic residues and true bitumens and their anthracitic residues. This distinction was first made by the late Dr. T. Sterry Hunt as long ago as $1863,{ }^{13}$ a distinction that has been too much lost sight of, and which is fundamental. This distinction is based on the fact that coals, schists and shales with their residues are nearly as insoluble in the solvents of bitumen as in distilled water; while all true bitumens are miscible with or 
almost wholly soluble in chloroform, a test that at once determines their relation to pyrobituminous minerals. The so-called asphaltic coals are not coals at all, but are the anthracitic residues of bitumens.

Having distinguished bituminous from non-bituminous minerals, the classification should, in my judgment, proceed upon the basis of chemical composition alone, either from the simple to the complex or the reverse. If from the simple to the complex, the first group or family would contain pure natural hydrocarbons, as occurring in nature, not separated in the laboratory. A second group might include compounds of carbon, hydrogen and oxygen; a third, compounds of carbon, hydrogen and sulphur; a fourth, compounds of carbon, hydrogen and nitrogen. A species should fall naturally under these groups, without regard to its physical condition, whether solid, liquid or gaseous, these physical conditions being merely accidents of occurrence, as I have elsewhere shown. Bitumens that are found to be mixtures of several of these groups, characterized by the predominance of one of them, may be classed under the group to which they are most closely allied.

In this way a classification may be effected for the purposes of pure science, and more particularly mineralogy, that can be readily modified for the purposes of technology. If it is urged that such a system is too intricate for the Petroleum Exchange, and that commercial differences exist among petroleums and other forms of bitumen generally of like composition, as, for instance, the oils of the Bradford field and those of the Lower country, I insist that commerce always has, and I presume always will, assume a lofty intelligence above the scientific world, of which the scientific world can take no note, because there are no points of contact between the two spheres of human activity.

There is, however, a limit to this divergence of interest and purpose that appears when a petroleum chemist is called upon to examine petroleum from a new locality and report upon its possible relations. It is, therefore, pertinent to inquire in what manner a new petroleum may be reported. There are now four, if not more, types of commercial petro- 
leum that rank relatively as follows, not intrinsically, but in commerce :

(I) Paraffine petroleums.

(2) Russian petroleums.

(3) Sulphur petroleums.

(4) Nitrogen petroleums.

The differences in these crude oils may certainly be regarded as specific, and they have been established upon the results of very elaborate analytical researches. Perhaps for commercial purposes the bestowal of specific names upon these varieties would not be understood or appreciated, but for the purposes of the laboratory they might be.

There is, however, in view of the knowledge we now possess, one aspect of this question that can well be considered by this congress and definite action urged upon both the experts in petroleum and their clients. This aspect is the extent to which the expert or the client is justified in demanding an examination of a specimen from a new locality, which shall be made by the elaborate analytical methods employed in the researches upon petroleum conducted during the last ten years.

My own judgment is that such an examination is fundamental, for such an examination is of importance from purely commercial considerations, to determine to which of the classes above enumerated any given specimen of petroleum belongs, for the oil may be in demand as a fuel, or for the manufacture of illuminating oil, or for the manufacture of lubricating oils. For either of these purposes it cannot be denied that the paraffine petroleums easily take the lead, as it requires no argument to prove that the more hydrogen gas is combined in any given liquid the greater number of heat units a pound of it will render available on combustion. Again, if it is desired to convert the petroleum into naphtha, high.grade kerosene and reduced oils, the paraffine petroleum will yield the largest return. Again, if the design is to treat the oil by cracking, the balance-sheet will show the largest profit in the conversion of paraffine petroleums.

Chemical science has not yet shown us how to add hy. 
drogen to compounds deficient in that element in any large way. In the laboratory of nature, by the alchemy of the sun, those mysterious processes go forward that rob hydrogen of its oxygen, and store it away for the service of man. I am not a believer in the chemical theories of the origin of bitumens.

If the paraffines are placed in the first rank for reasons based on pure science, the additive compounds of the benzole series should take rank as superior to the naphthenes, and they in turn as superior to the olifines, if the material is to be used simply for fuel purposes. For illumination any of them are decidedly inferior to the paraffines; if for cracking, the inferiority is still greater.

If sulphur is added by substitution to either the first or second class of petroleums, objectionable features are increased. Sulphur in equivalent proportions is greatly inferior to hydrogen as fuel. It is, however, in the manipulation of sulphur petroleums for illuminating purposes that difficulties appear. If a certain proportion of a paraffine petroleum is converted by substitution of one atom of sulphur for two atoms of hydrogen, and this atom of sulphur is afterwards wrested from its combination, the result is an olifine and not a paraffine.

It requires no argument to show that the more nitrogen an oil contains the less its value will be for fuel or illumination. The basic oils may be found in extremely small quantities even in paraffine petroleums, but when the percentage becomes large in an oil containing benzoles, and a small percentage, if any, of paraffines, the value of the products that may be obtained from such a petroleum for illumination becomes seriously impaired.

A crude petroleum is not necessarily determined as belonging strictly to either of these types, but it must, I think, approximate one of them. It therefore becomes of importance not only from the standpoint of pure science, but from that of commercial utility as well, to ascertain by the most careful examination the composition and relations of the various compounds that constitute the sample under examination. This course, while involving more time and 
expense, is, in the end, both more economical and more satisfactory than the time-honored expedient of distilling a pint from a glass retort and dividing the distillate into fractions of certain specific gravities, but of unknown composition.

\section{NOTES.}

${ }^{1}$ Report on Rock Oil or Petroleum. B. Silliman, Jr., New Haven, I855; American Chemist, 2, 18 ; Monit. Sci., No. 366 ; Am. Jour. Gas Lighting, 16, 83 ; Wagner's Jahresbericht, i872, p. 848.

${ }^{2}$ Bibliotheque Universelle, 4, 116; Ann. de Chimie et de Physique, II, 4, 314-340; London Jour. of Science, $\mathbf{3}, 4 \mathrm{I} \cdot \mathrm{I}$.

${ }^{3}$ Ann. de Chim. et de Phys., II, 64, I4I ; Jour. of the Franklin Inst., 24, I38; New Edinburgh Philos. Jour., 22, 97.

+ Ohio Agricultural Report, 18.59 (2d s.), p. 605.

${ }^{5}$ Reports of the Smithsonian Institution, 1862 ; Canadian Naturalist and Geologist; Am. Jour. of Science, II, 35, 157; Chemical and Geological Essays, 1875, pp. 169, 176-179.

${ }^{6}$ Reports and Awards, International Exhibition, 1876. General Report of the Judges of Group III, p. I55.

${ }^{\top} \mathrm{C}$. F. Mabery, Proc. Am. Acad. Arts and Sciences, 32, 121-176.

${ }^{8}$ C. M. Warren, Proc. Am. Acad. Arts and Sciences, 31, p. 56.

${ }^{9}$ Proc. Am. Philos. Soc., 10, 445. Geo. Survey California, Geology, II, Appendix, pp. 73-90.

${ }^{10}$ Am. Chemist, 2, 427 ; Chem. News 25, 46 ; Am. Journal Pharmacy, IV, 2. 313 .

${ }^{11}$ Am. Chemist, 4, 6.

${ }^{12}$ Proc. Am. Acad. Arts and Sciences, 31, I.

${ }^{13}$ Loc, cit.

\section{ELEMENTARY GRAPHICS AND GEOMETRY OF THERMODYNAMICS.}

BY ROBERT H. THURSTON.

(Concluded from p. 77.)

Proposition II.-If any substance is transferred from any one given thermodynamic state to another defined condition by a known path, and if the same transfer be effected by a second and different path, the difference in the quantity of heat absorbed or emitted in the two cases is measured, on a diagram of energy, by the area included between the lines representing the two paths; which area measured the difference in work done. Fig. 7. 